\title{
Mean Birth Weight and Mean placental Weight among Deliveries in a Tertiary Care Hospital
}

\author{
Raju Kafle, ${ }^{1}$ Kabiraj Nibedita, ${ }^{1}$ Binod Kumar Gupta' \\ 'Department of Paediatrics, Universal College of Medical Sciences, Bhairahawa, Nepal.
}

\section{ABSTRACT}

Introduction: Placenta is an organ that connects the developing fetus to the uterine wall to allow nutrient uptake, provide thermo-regulation to the fetus, waste elimination, and gas exchange. The present study was undertaken to look for mean birth weight and placental weight among deliveries in a tertiary care hospital.

Methods: A descriptive cross-sectional study was conducted in a tertiary hospital of Nepal. Ethical clearance was taken from institutional review comittee of hospital. Mothers with term and preterm gestation, their infants and the placentas were the subjects for the study. The study was conducted on 158 term and preterm deliveries. Placental weight, birth weight, gestational age, neonates' gender, weight, length and head circumference were recorded.

Results: The mean of weight of total 158 placentas was $449.24 \pm 82.07 \mathrm{~g}$ and the mean of birth weights was $2872.84 \pm 478.88 \mathrm{~g}$. Out of 158 deliveries, $138(87.4 \%)$ babies were of term gestation and $20(12.6 \%)$ babies were preterm.

Conclusions: Mean birth weight and placental weights are similar to that found on similar studies done on other hospitals. Knowing the mean placental weight and birth weight which relates to different functional dimensions of placenta and baby growth helps for further evaluation of placenta and baby.

Keywords: birth weight; maternal nutrition; placenta.

\section{INTRODUCTION}

Placenta plays a vital role in normal fetal development and failure of placenta to gain weight and insufficiency of its function can result in fetal disorders. It has been shown that placental weight has a significant role in fetal growth in terms of weight, body length, and cord length but it has no significant role in the presence of meconium-stained fluid. ' While some other studies have shown less correlation between above mentioned factors and placental weights. ${ }^{2}$

The placenta is attractive because of its availability and the ease with which it is measured and is also a cost- effective measure to correlate certain important aspects of health and disease. In Nepal, with the national efforts for "Safe motherhood Program", studies are essential on the pattern of fetal and placental growth. Also, the data on birth weight and placental weight are not available in context of Nepal.

The aim of this study was to look for mean birth weight

Correspondence: Dr. Raju Kafle, Department of Paediatrics, Universal College of Medical Sciences, Bhairahawa, Nepal. Email: drrajukafle2@gmail.com, Phone: +977-9857024748. 
and mean placental weight among deliveries in a tertiary care hospital of women in Bhairahawa Nepal.

\section{METHODS}

It is a descriptive cross-sectional study carried out among mothers with term and preterm gestation, and their infants at Universal College of Medical Sciences (UCMS), Teaching Hospital, Bhairahawa, Nepal from Jan 2012 to November 2012. Ethical clearance was taken from institutional review comittee of UCMS Teaching Hospital. Informed consent was obtained from all participants. All women with singleton pregnancy and all term, preterm and post term gestation delivered at births were included in the study. Intrauterine fetal death, women with unknown/ disputed gestational age, women with medical illnesses, pregnancy induced hypertension, eclampsia and preeclampsia, Neonates with congenital anomalies, women with twin/multiple pregnancy were excluded from the study. Placental weight, mean birth weight, gestational age, neonates' gender, weight, length and head circumference were recorded. Maternal age, weight, height were also noted and haemoglobin was estimated. The placental weight ratio, Ponderal index and maternal body mass index were calculated. These values were thus entered in a structured proforma.

Data collection was done by filling self-structured performa designed for the study. Data was collected throughout the study period. Convenience sampling was done and sample size was calculated using following formula:

\section{$n=Z^{2} s d^{2} / e^{2}$ where,}

$\mathrm{n}=$ minimum sample size

$\mathrm{Z}=$ for Confidence Interval of $90 \%$

$\mathrm{Sd}=$ standard deviation (1) from the pilot study done on $10 \%$ of the total sample size calculated.

$\mathrm{e}=$ maximum allowable error $=13 \%$

calculated sample size $=158$

Sample size of 158 was calculated. Data was analyzed using SPSS package.

\section{RESULTS}

Out of 158 deliveries, 138 (87.4\%) babies were of term gestation with mean placental weights of 455.76 $\pm 79.75 \mathrm{~g}$ and mean birth weights of $2939.93 \pm 431.82$ $\mathrm{g}$ and $20(12.6 \%)$ babies were preterm with mean placental weights of $405.25 \pm 85.75 \mathrm{~g}$ and mean birth weights of $2410 \pm 540.61$ g. Female: male ratio was
1.6. Mean and standard deviation of placental weights of term and preterm babies and mean and standard deviation of birth weights of term and preterm babies are observed (Table 1 and 2). The ratio of placental weight to birth weight was 1:6.6. The mean of placental weight was $15.85 \pm 2.87$ and the mean of birth weight/ birth length ratio was 59.65 \pm 8.83 . Percentiles for birth weights in different placental weight groups are calculated (Table 3).

Table 1. Mean and standard deviation of placental weights of term and preterm babies.

\begin{tabular}{|lll|}
\hline & Mean & S. D \\
Term $(n=138)$ & 455.76 & 79.75 \\
Preterm $(n=20)$ & 405.25 & 85.75 \\
\hline
\end{tabular}

Table 2. Mean and standard deviation of birth weights of term and preterm babies.

\begin{tabular}{|lll|}
\hline & Mean & S. D \\
Term $(n=138)$ & 2939.93 & 431.82 \\
Preterm $(n=20)$ & 2410.00 & 540.61 \\
\hline
\end{tabular}

\begin{tabular}{|c|c|c|c|}
\hline \multirow{2}{*}{$\begin{array}{l}\text { Corresponding } \\
\text { Percentiles of } \\
\text { birth weights }\end{array}$} & \multicolumn{3}{|c|}{ Placental weight groups } \\
\hline & $\begin{array}{l}300-400 \\
(n=22)\end{array}$ & $\begin{array}{l}401-500 \\
(n=87)\end{array}$ & $\begin{array}{l}501-600 \\
(n=36)\end{array}$ \\
\hline $3^{\text {rd }}$ & 1694.5 & 2179 & 2505 \\
\hline $10^{\text {th }}$ & 1765 & 2500 & 2600 \\
\hline $50^{\text {th }}$ & 2500 & 2900 & 3250 \\
\hline $90^{\text {th }}$ & 2980 & 3400 & 3500 \\
\hline
\end{tabular}

\section{DISCUSSION}

The mean placental weight of total 158 placentas in the present study was similar to the placental weights carried out by Pachauri et al which was 406.3 \pm $83.09 \mathrm{~g}^{3}$. However, the value was less than the value $529.7 \pm 113 \mathrm{~g}$, obtained by Asgharnia et al in Iran. ${ }^{4}$ The variations in the mean weight of the placenta may be due to variations in the methodology of preparing and weighing the placentas and may also be due to differences in nutritional status of mothers in different parts of world. Similar to our study, Heinonen et al. showed that placental actual weight was lower in Small for Gestational Age (SGA) infants than in Appropriate for Gestational Age (AGA) infants with the same birth weight. ${ }^{5}$ It seems that low birth weight should be related to low functional tissue mass of placenta; and this is accompanied by diminution of the area for exchange between mother and fetus, both at the villi and at fetal capillary surface area. Thus, the ability of exchanging oxygen and nutrition from mother to fetus is curtailed. 
The mean gestational age of the babies was $38.2 \pm 2.7$ weeks at birth. The infants' gestational age at birth was calculated from the last normal menstrual period. This is also similar to the recorded gestational age of the babies at delivery, using the Dubowitz method of estimation of gestational age, in an earlier study in Jos, which was $38.63 \pm 1.25$ weeks. $^{6}$

The mean birth weight of the babies delivered during the period of review was $2939.93 \pm 431.82 \mathrm{~g}$. This figure is higher than the mean birth weight $2.89 \pm 0.47 \mathrm{~kg}$ in an earlier study in 1999 in $\mathrm{Jos}^{6}$ and lower to the 3.167 \pm 0.45 recorded in Ilorin. ${ }^{7}$ The slight lower birth weight compared with that in llorin might be due to the higher altitude of that area where studied was done. The birth weight in this study was higher than that reported from Nnewi, Anambra state birth weight $2.89 \mathrm{~kg} .{ }^{8}$ The average birth weight of babies in an Indian study was reported as $2.8 \mathrm{~kg}^{9}{ }^{9}$ This is also lower than that in this study. The mean birth weight of the infants was higher in males compared with female babies, which is in agreement with reports from other centres. ${ }^{6,7}$

\section{CONCLUSIONS}

Mean birth weight and placental weight are similar to that found on similar studies done. Further the placental weight is dependent on maternal nutritional state. It has also been observed that placental actual weight was lower in SGA infants than in AGA infants with the same birth weight. Thus, weight of the placenta is amongst the simplest parameters that can be recorded easily and there can be the relation with pregnancy abnormality which is of great interest to clinicians.

Conflict of Interest: None.

\section{REFERENCES}

1. Lo Y-F, Jeng M-J, Lee Y-S, Soong W-J, Hwang B. Placental weight and birth characteristics of healthy singleton newborns. Acta Paediatr Taiwan. 2002;43(1):21-5. [Full Text]

2. Little RE, Zadorozhnaja TD, Hulchiy OP, Mendel NA, Shkyryak-Nyzhnyk ZA, Chyslovska N, et al. Placental weight and its ratio to birthweight in a Ukrainian city. Early Hum Dev. 2003;71(2):117-27. [PubMed | Full Text | DOI]

3. Pachauri S, Marwah SM. An anthropometric study of the newborn in a New Delhi urban community. Indian J Pediatr. 1971;38(7):291-7. [PubMed | DOI]

4. Asgharnia M, Esmailpour N, Poorghorban M, Atrkar-Roshan Z. Placental weight and its association with maternal and neonatal characteristics. Acta Med Iran. 2008;46(6):467-72. [Full Text]
5. Heinonen S, Taipale P, Saarikoski S. Weights of placentae from small-for-gestational age infants revisited. Placenta. 2001 May;22(5):399-404. [Full Text]

6. Pam SD. Assessment of the use of birth weight surrogates for the detection of low birth weight infants in Jos. West African College of Physicians, Lagos, 1999. [ㄷll Text]

7. Lawoyin TO. Maternal weight and weight gain in Africans: its relationship to birth weight. J Trop Paediatr. 1991;37(4):166-71. [PubMed | Full Text | DOI]

8. Azubuike JC. Incidence of low birth weight among eastern Nigerians. J Trop Paediatr. 1982; 28(6):270-2. [ㅁuMed | Full Text | DOI]

9. Athavale VB. A textbook of pediatrics. 2nd ed. New Delhi: Vikas Publishing House; 1989. 117 p. [Full Text] 